\title{
Impact of alternative energy sources on development of neo-industrial foreign trade specialization
}

\author{
Elena Andreeva ${ }^{1 *}$, Alla Golovina ${ }^{1}$, and Artem Ratner $^{2}$ \\ ${ }^{1}$ Ural State University of Economics, 8 Marta str. 62/45, 620144 Yekaterinburg, Russian Federation \\ ${ }^{2}$ Institute of Economics of the Ural Branch of Russian academy of sciences, Moskovskaya str. 29, \\ 620014 Ekaterinburg, Russian Federation
}

\begin{abstract}
This paper identifies the structure of the energy balance in the world and in individual countries was analyzed, trends and factors in the development of alternative types of energy carriers. The impact of their development on the volume and structure of international energy trade is substantiated. Its development prospects are presented for developed countries that are leaders in the development of alternative energy sources, and for developing countries for which the price factor is more important. Prospects of development of Russian energy exports in conditions of increasing importance of alternative types of energy carriers in the world economy and international trade are considered.
\end{abstract}

\section{Introduction}

Energy is very important in the life of mankind, for this reason it occupies a significant place in the structure of international trade. Energy export plays an important role for highly energy-rich countries; for the countries being not much provided with energy resources the import plays an important role. Therefore, Russia ranks $6^{\text {th }}(6.2 \%)$ in the world oil reserves, $1^{\text {st }}$ in the world natural gas reserves $(19.1 \%)$ and $2^{\text {nd }}$ in the world coal reserves $(15.2 \%)$ (see Figures 1-3 that follow).

Moreover, in terms of gas, the countries following from the $6^{\text {th }}$ position in terms of security have a resource of $4 \frac{1}{2}$ or more times less than Russia. As regards the coal, the countries following from the 6th position on security have a resource 4 and more times less than Russia.

Therefore, for Russia, as for a country being highly provided with energy resources, and as for a major exporter of oil and gas, despite the importance of diversification process, the energy export continues to be of high importance for filling the national budget and for creating the job places. In this regard, the hypothesis is proposed, that the development of alternative energy in the world and in the leading countries - importers of Russian energy resources have an impact on international energy carriers trade in general and Russian energy exports in particular. The purpose of the analysis is to investigate this hypothesis for confirmation or non-confirmation.

\footnotetext{
*Corresponding author: elenandr@mail.ru
} 


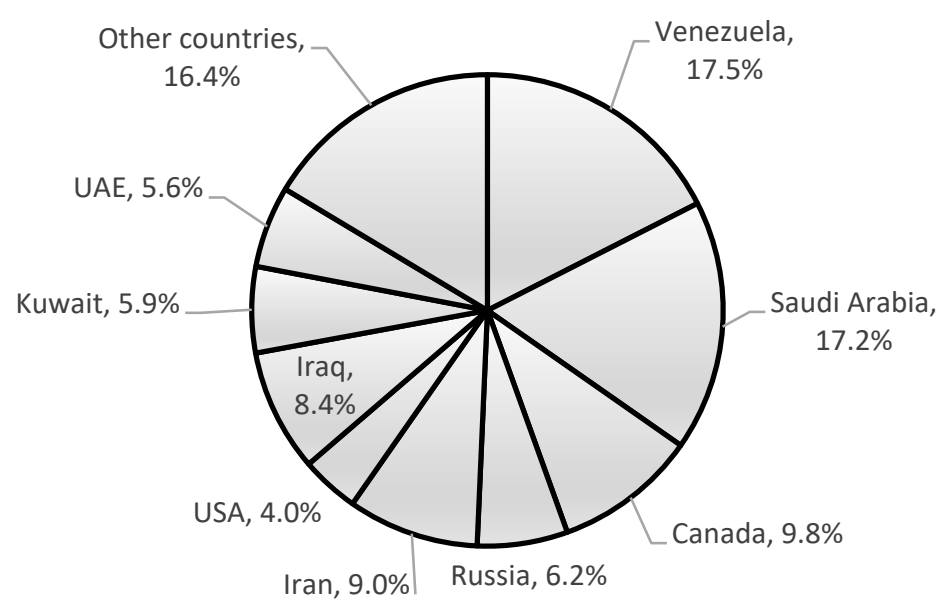

Fig. 1. Russia's share in global oil reserves at the end of 2019

Source: British Petroleum (2020)

The literature emphasizes that many countries, including those being provided with energy resources, attach great importance to the issue of depletion of the mineral resource complex. This depletion refers to the most important environmental indicators of subsoil use [1, p. 555]. It also appears to reflect the extent of pollution from these resources use (in the case of fuel resources: the scale of carbon dioxide emissions, of oil spills).

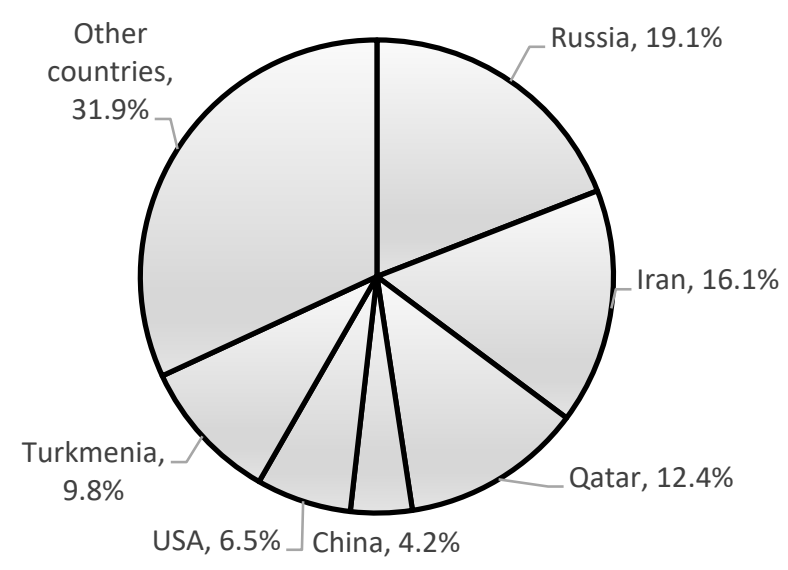

Fig. 2. Russia's share in global gas reserves at the end of 2019

British Petroleum (2020)

Other indicators being identified include the rate of waste generation during the subsoil resources' extraction, during the use and disposal of these wastes [2, p. 862]. 


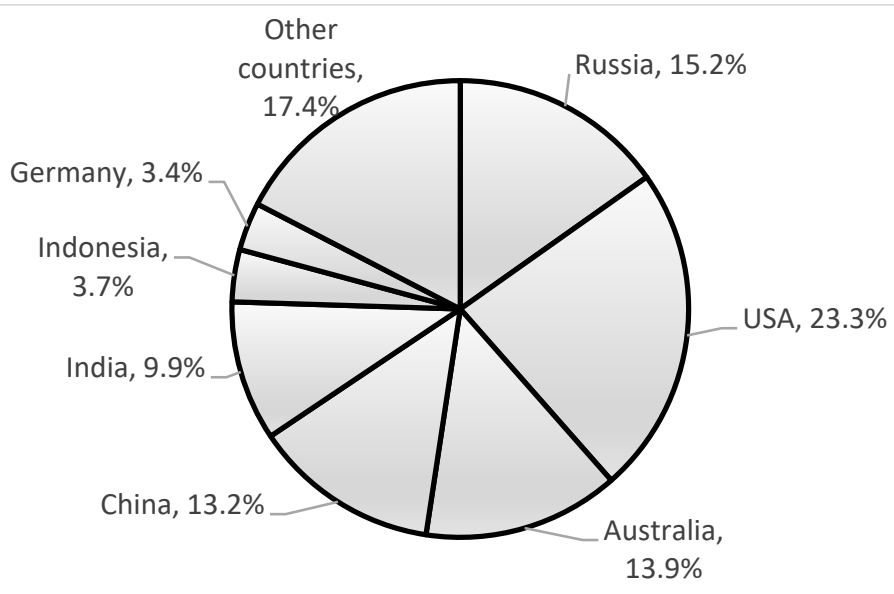

Fig. 3. Russia's share in global coal reserves at the end of 2019 Source: British Petroleum (2020)

Even the countries being provided with energy resources are set by search of technologies of energy saving and of low-carbon (i.e. alternative) power engineering [3, p. 23-24]. Energy conservation and the development of renewable energy sources are attractive even to foreign investors (as shown by studies on the example of almost two dozen of Central and South American countries) [4, p. 16]. Moreover, for Russia itself, the transition to a low-carbon development trajectory is recognized as relevant, which is associated with the requirements of international agreements [5, p. 672].

It is noted in the literature that even China, where coal accounts for $3 / 5$ of primary energy consumption, faces the problem of excessive coal mining capacity. On the basis of the analysis in research literature, the advantages of the variant of removal from the market of inefficient capacities are noted - against the variant of even reduction of all capacities [6, p. 1073, 1090-1091]. At that, the decrease in international demand for coal of a country (as on an energy carrier with the largest emissions of carbon dioxide) leads to a decrease in its exports, which leads to the closure of coal mines and, ultimately, to a decrease in the supply of coal for the national power engineering of this country [7, p. 11-12].

And the literature investigates the issues of country behavior in these conditions in the international market. In particular, an example is being explored of how a national economy is working on the problem of reducing the efficiency of coal industry and reducing foreign demand for coal due to climate policy. In particular, the example of Poland is taken: previously it was a major exporter of coal, and became a net importer [8, p. 263-264, 267].

As for the Russian economy, it is noted that in the conditions of global power transition to not carbon sources, the introduction of energy's economy is of great importance for it [9, p. 53-55, 62]. In order to generate export revenues in the case of a global energy transition, the falling part of raw export can be offset by the development of high-tech export. For this are important innovations, investments into them, the formation of a pool of specialists in the relevant industries, cooperation of large companies with small ones, including startups [10, p. 585]. In this context, it is emphasized that the comparative advantages of the Russian economy lie not only in the provision by energy resources, but also, for example, in developed technologies of nuclear energy mechanical engineering, which are attractive for developing countries. Therefore, taking into account the energy deficit in South Africa, Russia and other countries can enter its market with these technologies [11]. 
But energy carriers however continue to be a critical component of Russian export. Thus, the question remains be relevant of what prospects Russian energy carriers can have in the global hydrocarbon market, taking into account the development of alternative energy.

\section{Materials and methods}

It would be useful to analyze the structure of the energy balance in the world and in individual countries, to identify trends in the development of alternative energy carriers, as well as the volume and structure of international trade by energy carriers and the prospects for its development.

The development of alternative energy carriers is determined primarily by an array of factors. The development of the climate policy aimed at reducing the carbon dioxide emissions in the atmosphere in order to reduce the greenhouse effect, makes it more profitable to use the energy sources that produce energy with minimal carbon dioxide emissions. According to forecasts, by 2040, coal and oil will account for 50 to $42 \%$ of the global energy balance (depending on whether a conservative variant of energy consumption development will be implemented or an energy transition variant), gas - for $25-26 \%$, while alternative sources - for up 25 to $32 \%$. And this - despite the fact that 2015 coal and oil gave $59 \%$, gas $-22 \%$, and alternative sources $-19 \%$ (Figure 4 ).

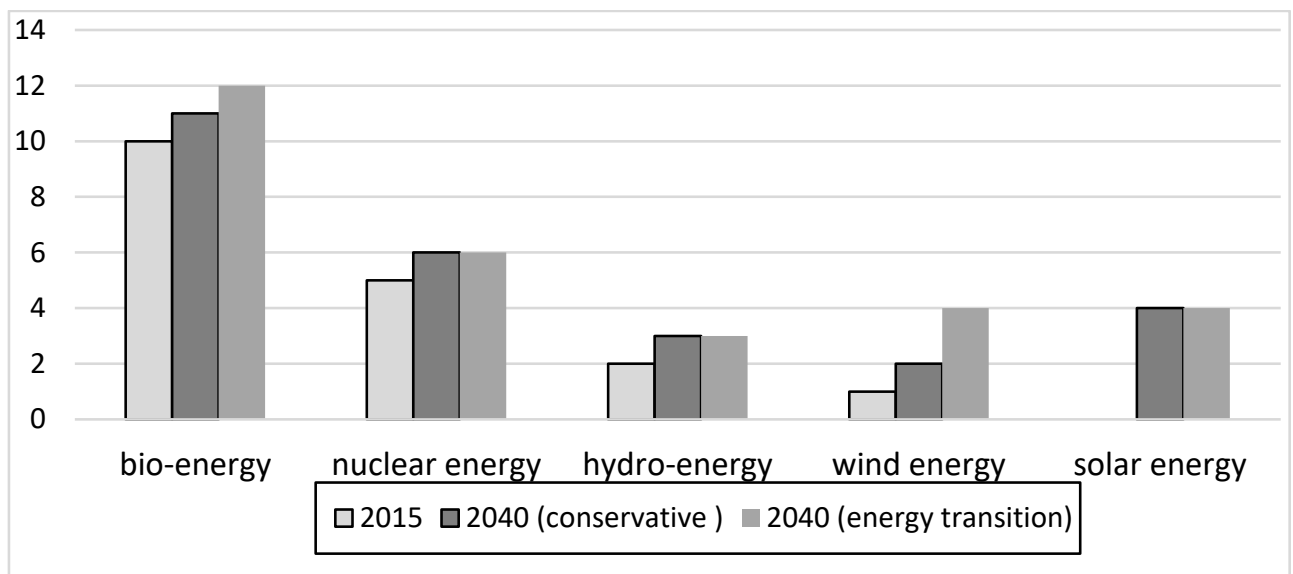

Fig. 4. Share of non-fuel energy sources in the global energy balance, $\%$ Source: British Petroleum (2020)

Thence, for example, in Germany 2019 renewable sources provide 46\% of the country's electricity. The use of energy resource, which gives the largest emissions of carbon dioxide, the coal, will be legally limited. By 2038, and if possible, by 2035, it is planned to stop all coal-fired power plants.

Economic stimulation's tools are also used. So, a fee for carbon dioxide emissions for industrial facilities was introduced: 2019 it amounted to 25 Euro/t, which made the gas electric generation more profitable than the coal one, due to the smaller specific size of emissions by gas power engineering. For the use of cars, this fee will be the same to 2021, and 2025 - 55 Euro/t, 2026 - 55-65 Euro/t. The transition of housing heating to renewable energy sources will be stimulated, including through hybrid heating systems. Since 2026, diesel boilers should not be installed or updated in new houses.

As a result, in 2019 the share of coal in electricity generation in Germany decreased: of the brown - by $22 \%$, of the stone coal - by $33 \%$. 
An important factor for the development of alternative energy carriers are safety considerations (within the framework of environmental policy), also being related to nuclear energy, especially after the disasters of Chernobyl (1986) and Fukushima (2011), taking into account the risk of man-made disasters and the issue of storage of spent nuclear fuel. In this regard, Germany also plans to stop the production of nuclear energy: about 2/3 of the number of nuclear power plants has already been stopped, and by 2022 it is planned to stop the remaining ones.

\section{Prospects of development of demand for energy resources in the world}

In general, the forecasted consumption of primary energy worldwide will increase by 2040 on $17-27 \%$ [12, p. 26]. The development of this segment in international trade is not even. If developed economies predominantly reduce energy consumption, then developing economies increase. In addition, as already noted, the commodity structure of this increase will be redistributed towards greener types of energy resources. This is illustrated by an example of the transport sector: the share of electricity in its energy balance grows rapidly (from $1 \%$ in 2015 to $11-32 \%$ in 2040 , depending on the implementation of a conservative variant or energy transition variant), the share of gas in the case of an energy transition grows (up to $6 \%$ ) (Table 1).

Table 1. Energy balance of transport sector, \%

\begin{tabular}{|l|r|r|r|}
\hline \multirow{2}{*}{ Power source } & \multirow{2}{*}{2015} & \multicolumn{2}{|c|}{2040} \\
\cline { 3 - 4 } & & \multicolumn{1}{|c|}{$\begin{array}{c}\text { Conservative } \\
\text { variant }\end{array}$} & $\begin{array}{c}\text { Energy } \\
\text { transition variant }\end{array}$ \\
\hline Oil products & 93 & 82 & 59 \\
\hline Electric power & 1 & 11 & 32 \\
\hline Gas & 4 & 4 & 6 \\
\hline Synthetic liquid fuel & 3 & 3 & 3 \\
\hline
\end{tabular}

Source: British Petroleum (2020)

At that, the share of coal in global energy consumption though is projected to decrease, but will continue to remain significant: it is expected by dynamics from $28 \%$ (2015) to $19 \%$ (2040) - and this if there is an energy transition to renewable energy sources (and in the case of a conservative scenario, the share will become 23\%) (Figure 4). The peak of coal consumption in the European Union and the Commonwealth of independent states was passed until 1990, but in Africa and the Middle East it is not expected to come until 2040 (and in a conservative scenario - also in the developing countries of Asia and South America) [12, p. 28-29]. Developing Asian countries are significantly ahead by the absolute volumes of coal use in electricity generation. Even in the case of an energy transition, their coal use will amount to about 6 thousand Terawatt-hour in 2040, or about $1 / 3$ of all energy sources in these countries. While in Europe these volumes will not exceed hundred - a couple of hundreds Terawatt-hour (that is a couple of percent) [12, p. 33]. Coal consumption growth by 2040 is expected in India (by $1 / 2$ million tons), in developing countries of Asia (except China); consumption will remain comparable to current levels in China and developed Asia. China and India will remain the largest consumers of coal $[12$, p. 62, 66].

This is due to the fact that in developing economies (of Asia and Africa), due to economic coercion, the more important factor is not the environmental friendliness of energy resource, but its cost, and here coal wins. 
Regarding the geographical reorientation of international trade in energy carriers, it can be noted that Russia, starting since increase of protectionism and international sanctions imposed in the 2010s, has to analyze the possibility of reorienting the export flows from developed to developing countries. One of the Russian important trading partners is China. In the context of coal export, it may be noted that in December 2020 China stopped the import of Australian coal (its scale is evidenced by the fact that it occupies the 2 nd position in Australian coal exports). This case shows that theoretically there are opportunities to find demand for Russian coal, in the case of the refusal of a number of developed countries, including Germany, from coal. However, the transport opportunities are in question here: the question is of the presence of a reserve for loading the railway leading on east.

Of mineral non-renewable fuels, only gas is projected to increase its share in global energy consumption by 2040: from 22 to 25-27\% (Figure 4). Including in Europe - on about 2-4 tens of billion cubic meters; in developing Asian countries (except China and India) - on 2 hundred; in China - on about 4 hundred billion cubic meters. In the countries actively pursuing the environmental policy, to the gas is given priority in electricity generation. So, in Europe, the number of terminals for receiving the liquefied natural gas (LNG) was increased.

At that, the gas production in Europe will decrease on a hundred billion cubic meters by 2040, while in Russia - will increase on 2 hundred billion cubic meters. But a comparable increase is expected also in the United States and in the rest of North America, in China, the Middle East, and Africa. At that, it is expected that unconventional (i.e. new) technologies will be increasingly used in gas production: biogas production, coal gasification, production of methane of coal beds, shale gas production, development of new fields, gas transfer to liquefied state for transportation [12, p. 56-57]. In these conditions of technological competition, Russia has to improve the production of natural gas and the logistics of its delivery, including its production in hard-to-reach areas and in harsh climatic conditions, liquefaction and delivery in such conditions. So, in 2017, gas production and LNG production were launched in the Arctic region - in Yamal. Gas liquefaction will be carried out using the latest technologies (modules for the construction of the plant were produced in China, Indonesia, Belgium), as well as transportation to foreign consumers (ice-class methane tankers were built in the Republic of Korea).

\section{Conclusions}

Thus, as the analysis has shown, the proposed hypothesis was confirmed: the development of the use of alternative (new) types of energy sources, conscious, environmentally conditioned, will affect international trade in energy resources, including Russian energy export. Demand for traditional fuels - coal, oil and gas - will remain high, but there will be a redistribution towards gas in the structure of energy consumption, on the background of a deliberate decrease in coal and nuclear energy consumption by several countries. Reducing the demand for traditional energy sources will lead to increased competition in international markets of their sale, which will force exporting countries to offer more competitive solutions (in terms of price, of convenience and speed of delivery), that will be possible for the exporter if new technological solutions are developed and implemented that reduce the cost of production, primary processing and logistics (delivery, storage) of resources. At that, the competition for markets of sale will occur in the context of the gradual depletion of the energy fields usual by availability level. New technological solutions will be also required by the development of more hardly accessible fields and by the organization of transportation of goods from hardly accessible areas.

Thus, the development of alternative energy will gradually reduce the demand for some Russian energy energetic commodities (coal; also oil), reorient Russian supply 
geographically to developing countries and form a request for the development of technicality, for the use of new technologies in the preparation of Russian fuel and energy export (for example, technologies for the development of hardly accessible gas fields, liquefaction and transportation of liquefied natural gas, including in harsh (Arctic) climatic conditions).

\section{Acknowledgements}

The article was prepared by financial support of RFBR (Russian Foundation for Basic Research), project number 20-010-00806-A.

\section{References}

1. V.G. Loginov, M.N. Ignateva, V.V. Yurak, Economy of Region, 16(2), 547 (2020)

2. I.G. Polyanskaya, V.V. Yurak, Economy of Region, 14(3), 851 (2018)

3. T.F. Agbanike, C. Nwani, U.I. Uwazie et al, Latin American Economic Review, 28, 8 (2019)

4. M. Ben Jebli, S. Ben Youssef, N. Apergis, Latin American Economic Review, 28, 2 (2019)

5. A.Y. Kolpakov, Studies on Russian Economic Development, 29(6), 665 (2018)

6. W. Wu, B. Lin, Computational Economics, 55(4), 1073 (2020)

7. M.C. Rademeyer, Mineral Economics (2021)

8. W. Suwala, Mineral Economics, 31(1-2), 263 (2018)

9. A.A. Makarov, Studies on Russian Economic Development, 31(1), 52 (2020)

10. E.L. Andreeva, E.V. Sapir, D.A. Karkh, I.A. Karachev, Economy of region, 15(2), 576 (2019)

11. H. Dkhili, Marketing and Management of Innovations, 3, 333-344 (2018)

12. Forecast of power engineering development in the world and in Russia, INEI RAN, "Skolkovo", https://energy.skolkovo.ru/ (2019) 